\title{
Effect of Process Condition in Plasma Electrolysis of Chloralkali Production
}

\author{
Nelson Saksono, Fakhrian Abqari, Setijo Bismo, and Sutrasno Kartohardjono
}

\begin{abstract}
Chlor-alkali is one of the most important processes in chemical industry. This process produces chlorine and caustic soda that becomes the main feedstock of daily needs products. In this study, the process condition on chlorine gas production by electrolysis plasma is examined. Plasma electrolysis can increase the chlorine gas production up to 24 times in single compartment reactor and can reach up to 59 times in double compartment reactor compared to electrolysis process. In reactor with single compartment, high voltage results high current then cause high-energy consumption. The highest chlorine gas production is at $0.5 \mathrm{M}$ and $300 \mathrm{~V}$ that results $4.63 \mathrm{mmol}$ within 15 minutes. On the other hand, using double compartment reactor, current is lower due to its higher distance between two electrodes that makes the higher resistance. In this case, the highest chlorine gas production is at $0.5 \mathrm{M} \mathrm{NaCl}$ and $700 \mathrm{~V}$ that results $11.25 \mathrm{mmol}$ within 15 minutes. The use of ion selective membrane can keep the movement of charge from one electrode to other. Ion selective membrane can separate side product of $\mathrm{NaOH}$, but side reaction of chlorine ion still exists.
\end{abstract}

Index Terms-Plasma electrolysis, voltage, concentration, depth, distance, ion-selective membrane.

\section{INTRODUCTION}

Chlor-alkali industry is one of the most important industrial sectors in chemical industry. This sector supports other sectors because its products can be used as raw materials in other industry. In Europe, chlor-alkali industry supported about $55 \%$ of chemical and pharmaceutical industries which gave profits up to 660 billion in 2009 [1]. Chlor-alkali Industry produces chlorine, hydrogen, caustic soda $(\mathrm{NaOH})$, hypochlorite, and other derivatives of chlorine from $\mathrm{NaCl}$ and water $\left(\mathrm{H}_{2} \mathrm{O}\right)$ as raw materials. Chlorine $\left(\mathrm{Cl}_{2}\right)$ and caustic soda $(\mathrm{NaOH})$ are two of ten chemical substances which are the most produced and used as raw materials of other daily products, such as: medicines, detergents, deodorants, plastics, herbicides, insecticides, disinfectants, etc. [2]. Chlor-alkali production needs much electrical energy to process the electrolysis of alkali solution $(\mathrm{NaCl})$. The cost for electricity in industry can reach until $70 \%$ of the selling price of the products [3]. Therefore, the effort to reduce the consumption of electrical energy in this industrial sector is needed by doing research to get more efficient method and technology.

Chlor-Alkali uses the electrolysis process to produce its products. Electrolysis is a method of compound's bonding separation by passing the electric current. Ionic compound,

Manuscript received July 29, 2013; revised September 30, 2013

The authors are with the Department of Chemical Engineering, Universitas Indonesia, Depok 16424, Indonesia (e-mail: nelson@che.ui.ac.id).
$\mathrm{NaCl}$, will be decomposed in the solvent and form ions in the solution. Positive discharge electrode is called anode and the negative one is cathode. Each electrode bonds ions which have different discharge, so that ions with negative discharge will go to anode and the positive ions will go to cathode. Nevertheless, electrolysis of $\mathrm{NaCl}$ solution (brine electrolysis) used in chlor-alkali production has significant weaknesses, those are low conversion resulted by the electrolysis process and the use of high electric current when the electrolysis process occur [4]. Hence, it is needed to observe other possible technologies that can be applied in the production of chlor-alkali to reduce the energy consumption.

One of the technologies that can reduce the energy consumption is plasma electrolysis. The plasma electrolysis process is similar with electrolysis process, but it is done with high enough voltage until the electric spark is formed producing the plasma on the electrolyte solution. The plasma will produce reactive species such as radicals on large amount which are accelerated by the sharp potential gradient and have enough kinetic energy to induce unique chemical changes in aqueous solutions, so it is able to increase the formation of products in solution several more times than the Faraday electrolysis process [5], [6]. Using this technology may reduce the energy consumption several times than conventional electrolysis so the productivity is more effective [6].

\section{METHOD}

The design of reactor is shown in Fig. 1. The reactor has two compartments where one compartment is equipped with graphite as anode and stainless steel as cathode in the other side. This reactor can also be modified as one compartment reactor by closing the connector between two compartments. The reactor is batch system made from acrylic housing filter connected with globe valve. The electric source is connected to 3-kVA-slide regulator with the output is then connected to $4 \mathrm{x}$ transformer. Diode Bridge is used to rectify the electric current. The current is measured and noted from ampere-meter Yuhua A830L.

The reactor design is also fulfilled with chlorine and hydrogen gas measurement. The chlorine gas produced is passed into KI $2 \%$ solution and hydrogen gas is passed into hydrogen analyzer. KI bonded the chlorine gas and reacted to form iodine that results the orange color in KI solution. Then, the solution was titrated by $\mathrm{Na}_{2} \mathrm{~S}_{2} \mathrm{O}_{3} 0.01 \mathrm{~N}$. This study analyzed the formation of plasma by varying $\mathrm{NaCl}$ concentration from $0.05 \mathrm{M}$ to $0.5 \mathrm{M}$ with voltage from $500 \mathrm{~V}$ $-700 \mathrm{~V}$. Furthermore, it measured the chlorine gas produced and calculated the energy consumption of the process. 


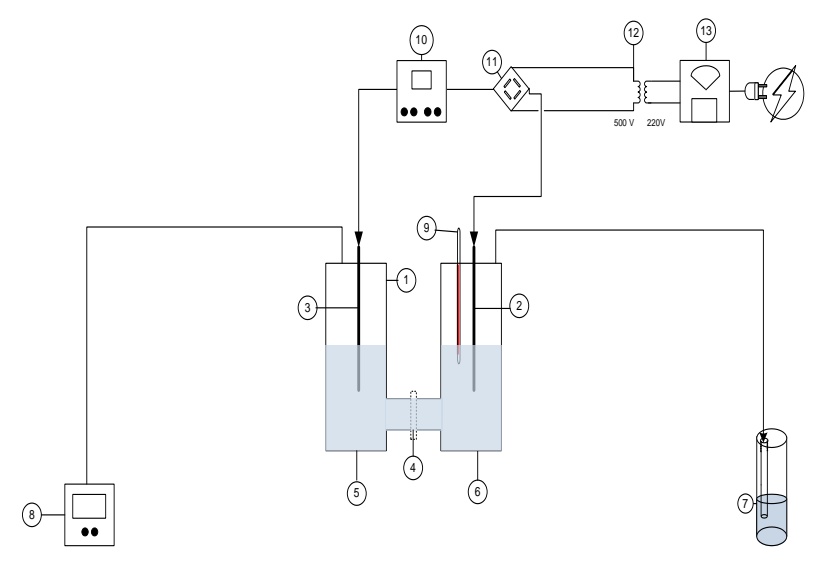
1. Reactor
2. Anode (Graphite)
8. Hydrogen Analyze
3. Cathode (Stainless Steel)
4. Connector
9. Thermometer
10. Ampere-meter
11. Diode "Bridge"
5. $\mathrm{NaCl}$ Solution (Catholyte) 12. Transformer
6. $\mathrm{NaCl}$ Solution (Anolite) 13. Slide Regulator
7. Bubbler of KI Solution

Fig. 1. Equipment configuration

\section{RESULTS AND DISCUSSIONS}

\section{A. The Effect of $\mathrm{NaCl}$ Concentration in Chlorine Gas Production}

The effect of concentration in chlorine gas production is shown in Fig. 2. Using $500 \mathrm{~V}$ as cell-voltage, the highest chlorine production is $5.78 \mathrm{mmol}$ for 15 minutes at $0.5 \mathrm{M}$ $\mathrm{NaCl}$. The lower concentration will also produce lower chlorine gas such as $0.05 \mathrm{mmol}, 0.11 \mathrm{mmol}, 1.96 \mathrm{mmol}$, and $2.16 \mathrm{mmol}$ for $0.1 \mathrm{M}, 0.2 \mathrm{M}, 0.3 \mathrm{M}$, and $0.4 \mathrm{M} \mathrm{NaCl}$ respectively. For $600 \mathrm{~V}$, chlorine produced is $0.09 \mathrm{mmol}$, $0.48 \mathrm{mmol}, 2.34 \mathrm{mmol}, 5.66 \mathrm{mmol}$, and $10.13 \mathrm{mmol}$ for each concentration from 0.1 to $0.5 \mathrm{M} \mathrm{NaCl}$ respectively. Furthermore, for $700 \mathrm{~V}$, chlorine produced is $0.16 \mathrm{mmol}$, $0.86 \mathrm{mmol}, 3.54 \mathrm{mmol}, 6.24 \mathrm{mmol}$, and $11.25 \mathrm{mmol}$ respectively.

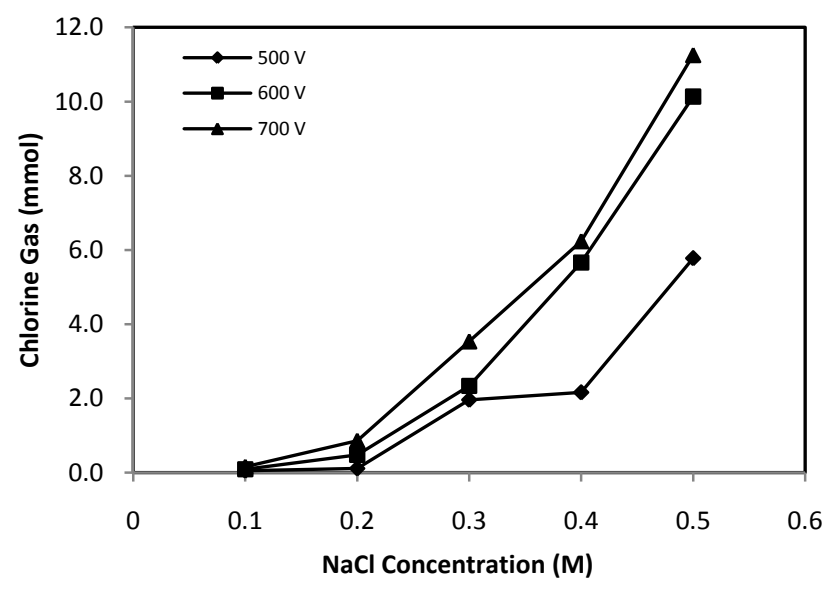

Fig. 2. The production of chlorine as a function of $\mathrm{NaCl}$ concentration within 15 minutes at $70-80^{\circ} \mathrm{C}$

Higher concentrations make the number of available chlorine in solution more. This can lead to the formation of chlorine radicals so that increased the production of chlorine. In addition to the amount of chlorine content in the solution, the higher the concentration will result to the higher conductivity in solution. Higher conductivity may cause the electrons move easily so that the chance of collisions between species in the solution increases [6], [7]. This collision makes the scattered energy becomes larger so that the radicals formed by the excitation of electrons in the ions are more [8].

\section{B. The Effect of Voltage in Chlorine Gas Production}

Fig. 3 shows the production of chlorine for 15 minutes of testing at a voltage of $500 \mathrm{~V}, 600 \mathrm{~V}$ and $700 \mathrm{~V}$. At a concentration of $0.1 \mathrm{M} \mathrm{NaCl}$, the production of chlorine gas is relatively low at $0.05 \mathrm{mmol}, 0.09 \mathrm{mmol}$, and $0.16 \mathrm{mmol}$. This is due to the unstable formation of plasma and more dominant electrolysis process. At a concentration of $0.2 \mathrm{M}$ $\mathrm{NaCl}$, the production of chlorine gas is higher than $0.1 \mathrm{M}$ that is $0.11 \mathrm{mmol}, 0.48 \mathrm{mmol}$, and $0.86 \mathrm{mmol}$. At this concentration, the plasma formed was not stable. However, the signs are formed plasma looks more stable than at a concentration of $0.1 \mathrm{M} \mathrm{NaCl}$. At a concentration of $0.3 \mathrm{M}$ $\mathrm{NaCl}$, the production of chlorine is $1.96 \mathrm{mmol}, 2.34 \mathrm{mmol}$, and $3.54 \mathrm{mmol}$. At a concentration of $0.4 \mathrm{M} \mathrm{NaCl}$, the production of chlorine is $2.16 \mathrm{mmol}, 5.66 \mathrm{mmol}$, and 6.24 mmol. Whereas at a concentration of $0.5 \mathrm{M} \mathrm{NaCl}$, the highest chlorine production reach $5.78 \mathrm{mmol}, 10.13 \mathrm{mmol}$, and 11.25 mmol

From the results obtained, the higher the voltage, the higher the chlorine produced. It is because of the plasma formed more stable and able to trigger more radicals that accelerate the rate of reaction in chlorine formation. Joule heating effect that will get bigger with the higher voltage affects plasma stability. This is due to the conversion of electrical energy into heat energy that makes the solution around the electrode evaporate (local vaporization solvent) to form gas sheath [9]. The formation of gas bubbles will trigger the collision between the gas bubbles with an electrical charge so that scattering of energy occurs and let the formation of plasma [10].

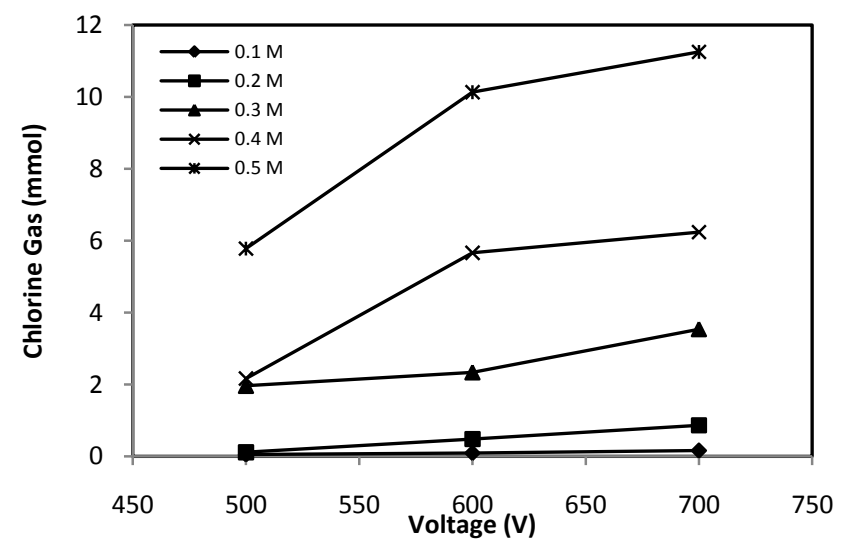

Fig. 3. Variation of voltage in chlorine gas production for 15 minutes at $70-$ $80^{\circ} \mathrm{C}$

From the results of voltage and concentration variation, it can be seen that the role of concentration over a major effect on the amount of chlorine gas product results. Both variables contributed each in the process of production of chlorine gas with the plasma electrolysis method. However, both have different influences. The voltage affects the plasma formation that in turn influences the formation of radical species in solution. However, the quantity of chlorine gas generated is more influenced by how much of the available chlorine in 
solution. Radical formation in solution has an influence on the reaction mechanism. Radicals have the ability to react faster than the other species. However, when the content of chlorine in the solution is limited, formed radical $(\mathrm{OH}$ radicals or other radical species) cannot encourage the production of chlorine gas.

\section{The Effect of Electrode Distance in Chlorine Gas Production}

One of parameters influence the activity of plasma is the distance between electrodes. Two compartments reactor has about $15 \mathrm{~cm}$ in distance between anode and cathode. It will cause the lower current flow due to higher resistance in the solution [11]. Energy consumption will be lower, however Joule heating effect to the solution will also lower. It makes the formation of gas sheath due to local solvent vaporization around the electrodes need longer time and cause plasma will be more difficult to form. In this study, condition is set in high voltage to make the electric current higher. It will cause to the higher Joule heating, so plasma can be easily formed.

Chlorine gas product yield is different between the two type of reactor (one and two compartment) caused by differences in both the operating voltage. For one compartment reactor with closer distance of electrode, the voltage is set to $200 \mathrm{~V}-300 \mathrm{~V}$. As for the two compartments reactor, the voltage is set to $500 \mathrm{~V}-700 \mathrm{~V}$. By seeing the difference voltage, the voltage on the reactor with a two compartments reactor is two times larger than the one compartment reactor. The results of chlorine gas products also have the same ratio that is 2 times. This explains the higher voltage can increase the production of chlorine gas in a linear fashion. Increase the voltage 2 times, can increase the production of 2 times anyway as shown in Fig. 4.

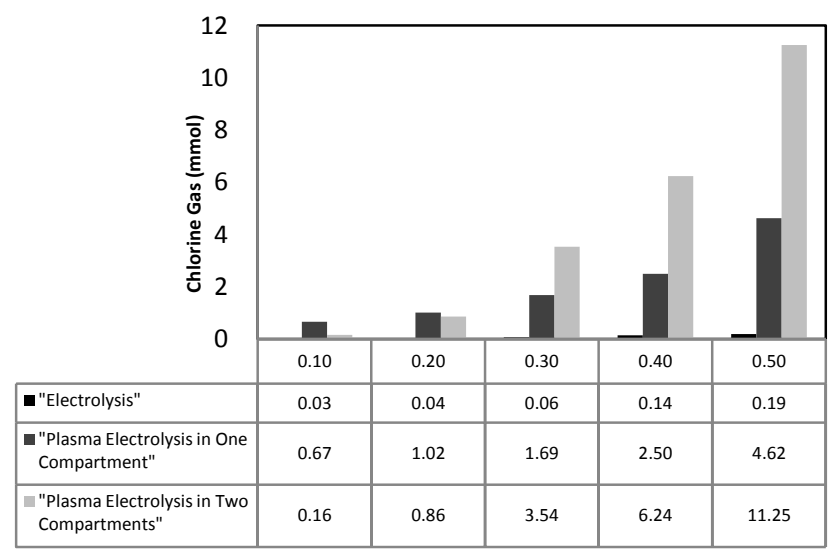

Fig. 4. Comparison of chlorine gas production for 15 minutes at $70-80^{\circ} \mathrm{C}$

\section{The Effect of Electrode Depth in Chlorine Gas Production}

One of the variables in this study is the depth of anode. The depth is set into three variations: on the surface of the solution, $1 \mathrm{~cm}$, and $2 \mathrm{~cm}$ below the surface of the solution. From the results of research conducted, the deeper the anode in the solution, then the electric current used is greater. The amount of current flow for anode at the surface of the solution is about $0.46 \mathrm{~A}$. Furthermore, the $1 \mathrm{~cm}$ depth is about $1.19 \mathrm{~A}$ and at $2 \mathrm{~cm}$ depth is $2.26 \mathrm{~A}$. If the currents are multiplied by the applied voltage (i.e. $300 \mathrm{~V}$ ), then it will obtain electric power consumed as shown in Fig. 5.

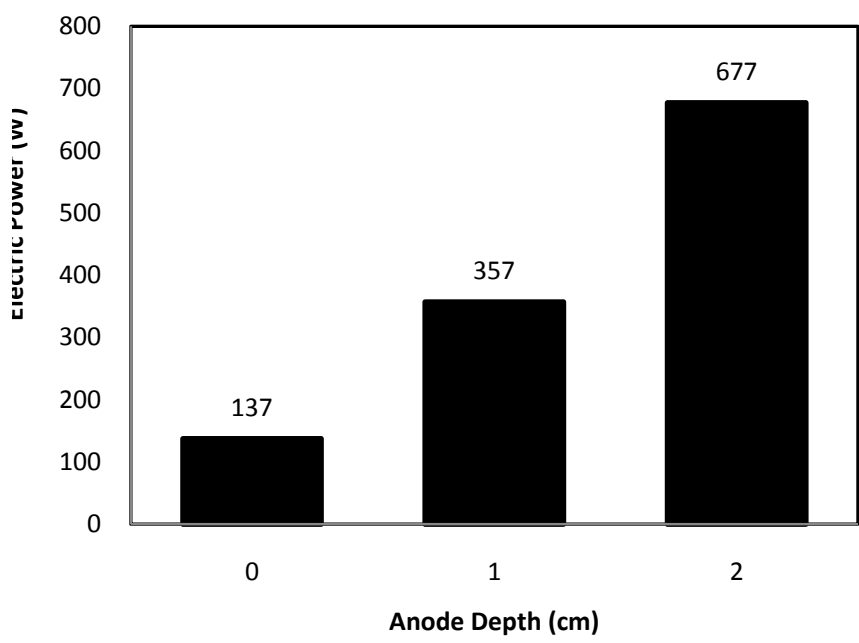

Fig. 5. Effect of anode depth to electric power in electrolysis process

The greater the electric current is caused by the wider of anode surface area to flow the current. Furthermore, the wider the surface area will make several zones in anode, electrolysis zone and plasma electrolysis zone. Because of the existence of electrolysis zone, the electric current becomes high. This zone can be minimalized by narrowing the surface area where the plasma formed (anode). In the research conducted by Sengupta (1994), it was stated that in lower and smaller electrode, the current density would be greater. It will increase the amount of heat energy (Joule Heating Effect) and will produce more vapor sheath in electrode surface area. The vapor formed will cover the anode and the electron excitation due to the potential difference will cause the formation of plasma. The existence of plasma will cause the electric current become lower and fluctuating [12].

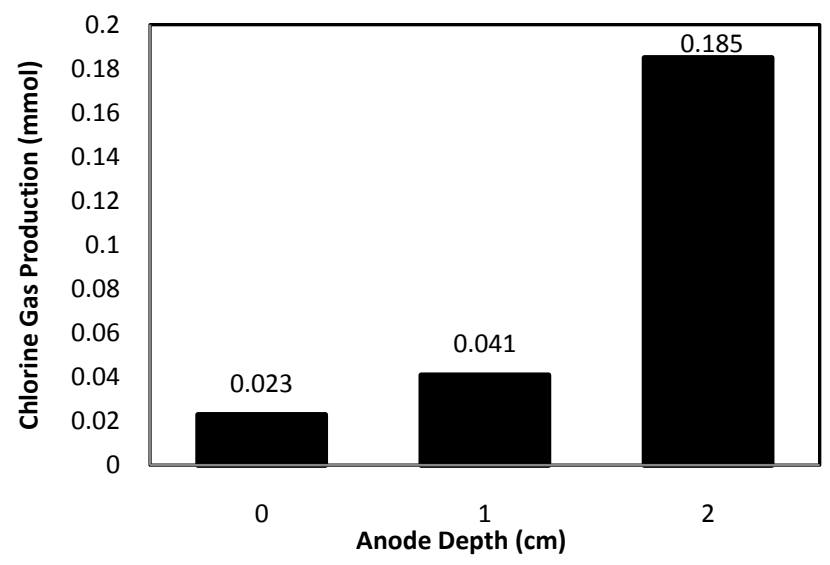

Fig. 6. Effect of anode depth to chlorine production in electrolysis process

Besides influencing the electric current, anode depth in the solution also affects the chlorine gas produced shown in Fig. 6 . The test is conducted by measuring the chlorine dissolved into KI solution for 5 minutes. From the test is resulted that the deeper the anode, the amount of chlorine gas produced is increase to. For anode on the surface of the solution, chlorine production is $0.023 \mathrm{mmol}$. Furthermore, for $1 \mathrm{~cm}$ and $2 \mathrm{~cm}$ depth, chlorine productions are $0.041 \mathrm{mmol}$ and $0.185 \mathrm{mmol}$ respectively as shown in Fig. 5. The depth will influence in vapor sheath production in anode surface. The wider the anode covered by vapor sheath, so the plasma formed will be 
bigger [13]. It will increase the amount of compound decomposed to form radical species that then produced the chlorine gas. Nevertheless, the wider area of anode surface will let the zone of electrolysis exists and the electric current will be higher although more products formed.

\section{E. The Effect of Membrane Selective Ion Usage in Plasma Electrolysis Process}

In-situ separation technology using ion selective membranes in chlor-alkali production process is commonly used in the industry. In this study, the use of ion-selective membranes is tested to see its effect on plasma formation and productivity of the process. The purpose of the use of ion-selective membrane is to reduce the potential for adverse reactions that cause the production of chlorine gas is not optimal.

In this study, ion selective membrane is installed between the anode and cathode compartments. At the anode compartment contains $0.5 \mathrm{M} \mathrm{NaCl}$ solution and the cathode compartment contains distilled water. Different design solutions in both compartments following the existing design in the chlor-alkali industry. This system will make the anode compartment containing $\mathrm{NaCl}$ will produce chlorine gas and cathode compartments were filled with water to produce hydrogen gas and a solution of $\mathrm{NaOH}$ as shown in Fig. 7.

Displacement of the charge on the ion selective membrane is affected by the conductivity of the membrane that is expressed as proton conductivity in the membrane. Charge transfer mechanism (proton) can be explained by the areas contained within the membrane. The first area is the area that is formed from the hydrophobic polymers of fluorocarbons and hydrophilic regions containing sulfonate groups, protons, and hydration water. Between the two regions, there is a central region (intermediate) that has the character of both areas. Hydrophobic fluorocarbon chain and hydrophilic sulfonate group is set to maximize the interaction between the membrane fragments. This led to the formation of the grouping ion hydration in aqueous phase at fluorocarbons area. Research that has been done indicates that proton transfer occurs between groups' ions (protons) due to proton transfer in the sulfonate group [14].

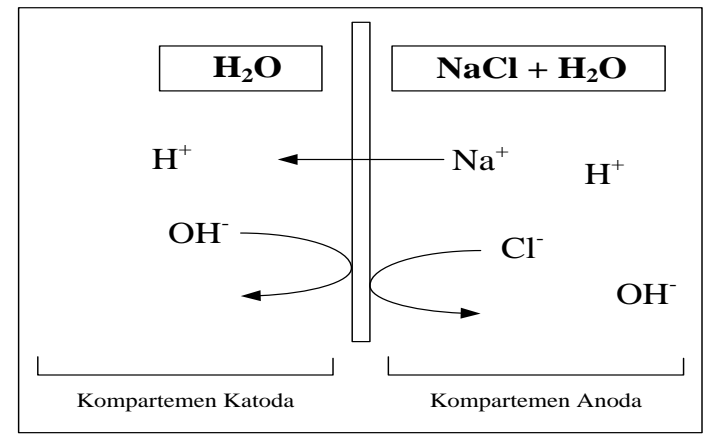

Fig. 7. Ion movement in ion-selective membrane system

In this study, the measured of current flow on ampere-meter are very small. At a concentration of $0.5 \mathrm{M}$ $\mathrm{NaCl}$ using reactor without membranes, currents may reach 1-2 A. However, when the membrane is installed, the flow is only in the range of $0,1-0,3 \mathrm{~A}$. Resistance of the membrane quite high causes this phenomenon. Research conducted by Slade et al (2002) showed that the conductivity of the ion-selective membrane (Nafion $\AA$ ) is low [14]. This causes the current to be small as shown in Fig. 8.

The use of ion-selective membrane may inhibit the transfer of charge from one electrode to the other electrode. This phenomenon resists the plasma to be formed. Based on Fig. 8, the current characteristic does not seem similar to that in plasma electrolysis where there is a point of critical currents and fluctuations thereafter.

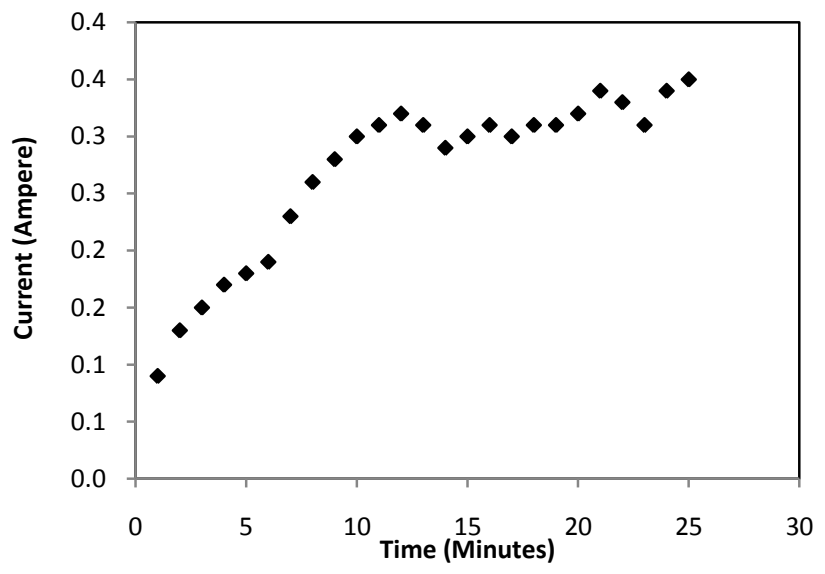

Fig. 8. Current change in process with ion-selective membrane system

In the Fig. 8, the longer the flow is increasing. On the observations made, the higher the current due to the increase of temperature in the system. Initial temperature was $29^{\circ} \mathrm{C}$ and gradually increased up to $35-40^{\circ} \mathrm{C}$. Along with increasing temperature, conductivity of ion-selective membrane (proton conductivity) increases [8]. This causes the current to increase. However, current and voltage are regulated is not strong enough to create the effect of Joule heating at the anode so that the plasma is not formed and the process is dominated by the electrolysis.

\section{CONCLUSION}

The application of plasma electrolysis can be implemented in the production of chlor-alkali. At the time of the plasma formed, the current will fluctuate and gradually decline. It can reduce the amount of energy consumption because it can run with lower current with the same voltage condition. The higher the concentration and voltage will lead to the increase of production of chlorine gas. Radicalization process will produce active species that can make the reaction mechanism becomes unusual. It will lead to the faster gas product formation process for about $11.25 \mathrm{mmol}$ compared to electrolysis process which is only $0.19 \mathrm{mmol}$. Furthermore, the anode depth also affects the production of chlorine. The wider the surface area of anode in the solution, the production of chlorine is increase, but the power consumption is also increase. The use of ion-selective membrane can inhibit the transfer of charge from one electrode to the other electrode. This makes the plasma cannot be established.

\section{ACKNOWLEDGEMENT}

Directorate General of Higher Education, Ministry of Education Republik Indonesia and Directorate of Research and Community Service Universitas Indonesia supported this work as funding scheme of BOPTN 2013. 


\section{REFERENCES}

[1] E. C. Committee, "An Electricity Intensive Sector Exposed to Carbon Leakage," In: CHLOR, E. (ed.), The European Chlor-Alkali industry, Brussels: Celfic, 2010.

[2] T. Bommaraju, P. J. Orosz, and E. A. Sokol. (2011). Brine Electrolysis. [Online]. Available: http://electrochem.cwru.edu/encycl

[3] R. Santorelli and A. Schervan, "Energy Production from Hydrogen Co-Generated in Chlor-Alkali Plants by the Means of Pem Fuel Cells Systems," Nuvera Fuel Cells Europe, Via XXV Aprile 2, 2009.

[4] H. K. Abdel-Aal, S. M. Sultan, and I. A. Hussein, "Parametric Study for Saline Water Electrolysis - part i: Hydrogen Production," International Journal of Hydrogen Energy, vol. 18, no. 6, pp. 485-489, 1993.

[5] N. Saksono, B. Ariawan, and S. Bismo, "Hydrogen Productions System Using Non-Thermal Plasma Electrolysis in Glycerol-KOH Solution," International Journal of Technology, vol. 1, pp. 8-15, 2012.

[6] T. Mizuno, T. Akimoto, K. Azumi, T. Ohmori, Y. Aoki, and A. Takahashi, "Hydrogen Evolution by Plasma Electrolysis in Aqueous Solution," Japanese Journal of Applied Physics, vol. 44, no. 1A, pp. 396- 401, 2005.

[7] J. H. Chaffin, S. M. Bobio, and H. Inyang, "Hydrogen production by Plasma Electrolysis," Journal of Energy Engineering, ASCE, vol. 132, no. 3, pp. 104-108, 2006.

[8] A. Slade, S. A. Campbell, T. R. Ralph, and F. C. Walsh, "Ionic conductivity of an extruded Nafion 1100 EW series of membranes," Journal of the Electrochemical Society, vol. 149, no. 12, pp. A1556-A1564, 2002.

[9] S. K. Sengupta, A. K. Srivastava, and R. Singh, "Contact glow discharge electrolysis: a study on its origin in the light of the theory of hydrodynamic instabilities in local solvent vaporization by Joule heating during electrolysis," Journal of Electrochemical Chemistry, vol. 427, pp. 23-27, 1997.
[10] R. C. C. Moustakas, "Demonstration Plasma Gasification- Vitrification System for Effective Hazardous Waste Treatment," Journal of Hazardous Materials, vol. B123, pp. 120 - 126, 2005.

[11] C. B. Wei, X. B. Tian, S. Q. Yang, X. B. Wang, R. K. Y. Fu, and P. K. Chu, "Anode current in plasma electrolytic oxidation," Surface and Coatings Technology, vol. 201, pp. 5021-5024, 2006.

[12] S. K. Sengupta and O. P. Singh, "Contact glow discharge electrolysis: a study of its chemical yields in aqueous inert-type electrolytes," Journal of Electroanalytical Chemistry, vol. 369, pp. 113-120, 1994.

[13] X. L. Jin, X. Y. Wang, H. M. Zhang, Q. Xia, D. B. Wei, and J. J. Yue, "Influence of Solution Conductivity on Contact Glow Discharge Electrolysis," Plasma Chem Plasma Process, vol. 30, pp. 429-436, 2010.

[14] A. Slade, S. A. Campbell, T. R. Ralph, and F. C. Walsh, "Ionic conductivity of an extruded Nafion 1100 EW series of membranes," Journal of the Electrochemical Society, vol. 149, no. 12, pp. A1556-A1564, 2002.

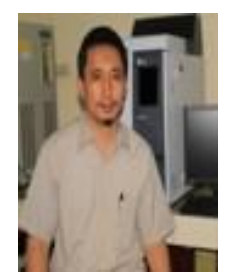

Nelson Saksono and his group are now doing research in application of plasma electrolysis technology for Hydrogen and chlor production, and wastewater treatment. Results of his research have been published in several international journals/seminars in the last three years. Plasmas in liquids are already being used in nanoscience for nanoparticle, film growth and surface functionalisation. The pressing issue in optimizing and extending the use of plasmas in liquids is to understand the plasma-induced physical and chemical phenomena exhibited in current, well defined applications. This understanding can then identify and inform the implementation of other potential applications. 